\title{
COVID-19, SAÚDE E VULNERABILIDADE SOCIOESPACIAL NA CIDADE DE VITÓRIA/ES
}

\section{COVID-19, HEALTH AND SOCIAL-SPATIAL VULNERABILITY IN THE CITY OF VITÓRIA_ES}

Liziane de Oliveira Jorge ${ }^{1}$, Luciene Pessotti ${ }^{1}$

\section{RESUMO:}

O presente trabalho analisa o comportamento e as consequências do novo coronavírus (COVID-19) na cidade de Vitória/ES, a partir da disponibilidade de dados públicos abertos sobre a doença, com ênfase no conteúdo e granularidade, com extração de indicadores que permitem estabelecer uma correlação socioespacial da enfermidade por bairros. Objetiva avaliar o processo de disseminação da doença no território desde o estágio inicial, bem como, as comorbidades da população contaminada e sua correlação com a localização. $O$ trabalho extrai diretamente da planilha de dados abertos os microdados desejados, submete ao tratamento estatístico, e procede à criação de mapas georreferenciados com cruzamentos de informações oriundas de outras bases de dados. Estes dados são fundamentais para compreender a relação socioespacial da doença, como renda, saneamento, zoneamento urbano e educação alimentar e nutrição. $O$ trabalho comprova as consequências da vulnerabilidade diante da relação assimétrica de saúde que afeta a população infectada pelo novo coronavírus. As mortes se situam predominantemente em áreas precárias, afetam indivíduos pobres, com a saúde debilitada e que historicamente habitam as áreas informais de Vitória sem direito à cidade.

PALAVRAS-CHAVE: Coronavírus; Saúde urbana; Georreferenciamento; Transparência pública.

\begin{abstract}
:
This paper analyzes the behavior and consequences of the new coronavirus (COVID-19) in the city of Vitória/ES, from the availability of open public data on the disease, with an emphasis on content and granularity, with the extraction of indicators that allow establishing a socio-spatial correlation of the disease by neighborhood. It aims to evaluate the process of spreading the disease in the territory since the early stage, as well as to evaluate the comorbidities of the contaminated population and its correlation with the site. The work extracts the selected microdata directly from the open data spreadsheet, submits it to statistical treatment, and proceeds to create georeferenced maps with information crosses coming from other key databases for understanding the socio-spatial relationship of the disease, such as income, sanitation, zoning law and food education and nutrition. The work demonstrates the consequences of vulnerability in the face of the asymmetrical health relationship that affects the population infected with the new coronavirus since deaths are situated predominantly in precarious areas, affecting poor people, in poor health and that historically inhabit the informal areas of Vitória without the right to the city.
\end{abstract}

KEYWORDS: Coronavirus; Urban health; Georeferencing; Public transparency.
Fonte de Financiamento: Pesquisa desenvolvida na Universidade Federal do Espírito Santo, sem Agência de Fomento.

Conflito de Interesse: Os autores declaram não haver conflito de interesse.

Ética em Pesquisa: Os autores declaram não haver necessidade.

Submetido em:

28/10/2020

Aceito em: 18/06/2021 


\section{A TRANSPARÊNCIA DE DADOS PÚBLICOS SOBRE A COVID-19}

A pandemia da COVID-19 foi decretada oficialmente pela Organização Mundial da Saúde (OMS) em 11 de março de 2020i. Passados mais de um ano de pandemia, a transparência dos dados públicos compreende a principal diretriz para que se possa analisar e compreender as informações sobre a disseminação da COVID-19 no país e orientar procedimentos e políticas públicas de enfrentamento à crise pandêmica. 0 Brasil, até o início de abril de 2021, situavase em segundo colocado no ranking de óbitos mundiais em valores absolutos. 0 país contava com aproximadamente 345 mil mortos, e computava mais de 13,2 milhões de casos acumulados, ocupando o segundo lugar entre os países com a maior quantidade de infectados, situando-se no epicentro da pandemia da América Latina e no mundo (BRASIL, 2021).

O Governo Federal mantém uma base de dados por Unidade de Federação, com atualização diária, com informações sobre a Covid-19 e a Síndrome Respiratória Aguda Grave (SRAG). Através do Painel Coronavírus (BRASIL, 2021), são divulgados os dados de casos confirmados, recuperados, óbitos, indicadores de letalidade e mortalidade, ocorrências acumuladas, dentre outros. O Painel dispõe de gráficos interativos e mapas para estabelecer um comparativo entre os estados. As assimetrias existentes no território nacional ficam evidentes quando se avaliam os dados do portal. Observa-se que as fontes de todos os dados são provenientes das Secretarias Estaduais de Saúde das 27 Unidades Federativas brasileiras. Diante da amplitude do território nacional e da crise instaurada em decorrência dos problemas de gestão na área da saúde, inclusive em âmbito federal, cada Estado da Federação buscou atuar de forma independente e autônoma no enfrentamento à pandemia.

Nesse sentido, a divulgação de dados brutos, ou seja, abertos, é crucial para o exercício do direito à cidadania, enquanto um recurso democrático de acesso às informações primárias, verídicas, atualizadas, sem manipulações prévias ou códigos de difícil interpretação. No que tange à saúde e à emergência sanitária, a Lei Federal n.o 13.979, de fevereiro de 2020 (BRASIL, 2020), dispõe de medidas para o enfrentamento da emergência de saúde pública de importância internacional, decorrente do novo coronavírus, responsável pelo surto de 2019. 0 Art. $6^{0}$ da referida lei estabelece o compartilhamento entre órgãos e entidades da administração pública federal, estadual, distrital e municipal de dados essenciais à identificação de pessoas infectadas ou com suspeita de infecção pelo novo coronavírus, com a finalidade exclusiva de evitar a sua propagação. Além disso, a Lei atribui ao Ministério da Saúde a responsabilidade pela manutenção dos dados públicos atualizados sobre os casos confirmados, suspeitos e em investigação, resguardando o direito ao sigilo das informações pessoais (BRASIL, 2020).

Convém ressaltar que o Espírito Santo buscou, desde o início da pandemia, implementar mecanismos eficientes para informar a população sobre a crise sanitária, ao disponibilizar publicamente dados municipais detalhados das ocorrências da doença. 0 Estado se antecipou nesta divulgação e criou um painel interativo com informações completas sobre a COVID-19, gerenciado pela Empresa de Processamento de Dados do Estado do Espírito Santo (PRODEST). Essa iniciativa aponta o protagonismo na gestão pública e de dados, com integração eficiente entre Secretarias e transposição tecnológica de dados, especialmente as informações provenientes do Sistema de Informação em Saúde e-SUS Vigilância em Saúde (VS). Segundo os Boletins emitidos pela Open Knowledge Brasil (OKBR, 2020), em maio, julho e agosto de 2020 o ES ocupou o topo do ranking dos estados com o maior índice de transparência no país. Esta colocação foi conquistada a partir da divulgação atualizada de 26 indicadores distribuídos em três temas essenciais: i. conteúdo (casos, demografia, infraestrutura de saúde, testagem), ii. granularidade (base de dados e microdados) e, iii. 
formato (acesso e qualidade) (Tabela 1). 0 lema da entidade OKBR (2020) é: "dados abertos ajudam a salvar vidas". Conforme a divulgação do último Boletim da entidade, de dezembro de 2020, o Estado do Espírito Santo mantém o alto nível de transparência, com a terceira melhor colocação no ranking.

\begin{tabular}{|c|c|c|}
\hline \multicolumn{2}{|c|}{ Tabela 1. Índice de Transparência da Covid-19 e indicadores nas três dimensões: } \\
1. Conteúdo, 2. Granularidade e 3. Formato
\end{tabular}

O Espírito Santo, através do Painel Covid-ES (ESPÍRITO SANTO, 2020), dispõe de dados completos detalhados dos pacientes para todos os municípios do estado, por raça, idade, escolaridade, gênero, bairro, sintomas, categorias de comorbidades, critério de confirmação, investigação de viagem dentro ou fora do país e, também, se o mesmo ficou internado. É possível avaliar a evolução da doença, em especial, a identificação de curas e óbitos, bem como, acompanhar o percentual de letalidade, a progressão e o ranking dos dados selecionados por bairro, municípios ou regiões.

O sítio eletrônico do Painel Covid-ES (ESPÍRITO SANTO, 2020) apresenta mapas interativos para todo o Estado, por municípios e por bairros, relacionando casos confirmados e óbitos. Além destas informações, possui gráficos que auxiliam a leitura conforme os dados selecionados no painel. Todos os dados estão abertos, em planilhas para tabulação por qualquer cidadão. Entretanto, apesar do Espírito Santo dispor de dados abertos e painéis interativos para o acompanhamento didático e ágil da doença, as consequências em âmbito socioeconômico e a espacialização territorial da COVID-19 necessitam de aprofundamento de informações para a compreensão de seus impactos enquanto um complexo fenômeno urbano. Diante disso, este trabalho propõe um olhar mais apurado sobre a pandemia no município de Vitória, capital e lugar de sinergia e centralidade em âmbito metropolitano e estadual.
Tabela 1. Índice de Transparência da Covid-19 e indicadores nas três dimensões: 1. Conteúdo, 2. Granularidade e 3. Formato.

Fonte: Adaptado da Metodologia do Open Knowledge Brasil para a Transparência COVID-19 2.0. (OKBR, 2020). 


\section{EVOLUÇÃO URBANA E VULNERABILIDADE EM VITÓRIA}

A cidade de Vitória data do período colonial e é uma das mais antigas no Brasil. Parte de seu território está situado em uma ilha constituída por um Maciço Central que é o relevo de maior identidade da cidade e, delimitado por uma vida marinha marcada pela existência de extensos manguezais em sua porção oeste, praias na região leste e continental, e canais navegáveis, sendo um canal portuário ao sul da baía e outro ao norte. 0 seu território dispõe de muitas áreas inadequadas para urbanização (morros e mangues), o que restringe as zonas disponíveis para expansão urbana, que se orienta para outros municípios da Região Metropolitana da Grande Vitória (BID, 2018). Sua área territorial é 97,123 $\mathrm{km}^{2}$ (IBGE, 2021a). A cidade possui $63,97 \mathrm{~km}^{2}$ de área urbana e $52,36 \mathrm{~km}^{2}$ de região urbanizada (IJSN, 2011b). Com uma população estimada em 365.855 habitantes possui Índice de Desenvolvimento Humano Municipal (IDHM) de 0,845 (IBGE, 2021), o 4o melhor no Brasil (PMV, 2020). A expectativa de vida na capital é de 76 anos (PMV, 2015). A cidade integra a Região Metropolitana da Grande Vitória que concentra 48\% da população estadual (IBGE, 2010)

Um traço marcante do processo de urbanização da cidade consiste na conquista de áreas através de sucessivos aterros, condição que redefiniu todo o entorno "[...] da ilha principal e continente quanto no ambiente marinho (baía, canal, áreas alagadas e oceano) do município de Vitória, totalizando 15,74 $\mathrm{km}^{2}$ " (COELHO, 2017, p.772). Os aterros viabilizaram novas conexões viárias, loteamentos, áreas de lazer e ampliação de zonas portuárias e aeroportuárias (Figura 1).

Figura 1. Mapa de aterros de Vitória e localização das ZEIS, 2020.

Fonte: Os autores, 2020.

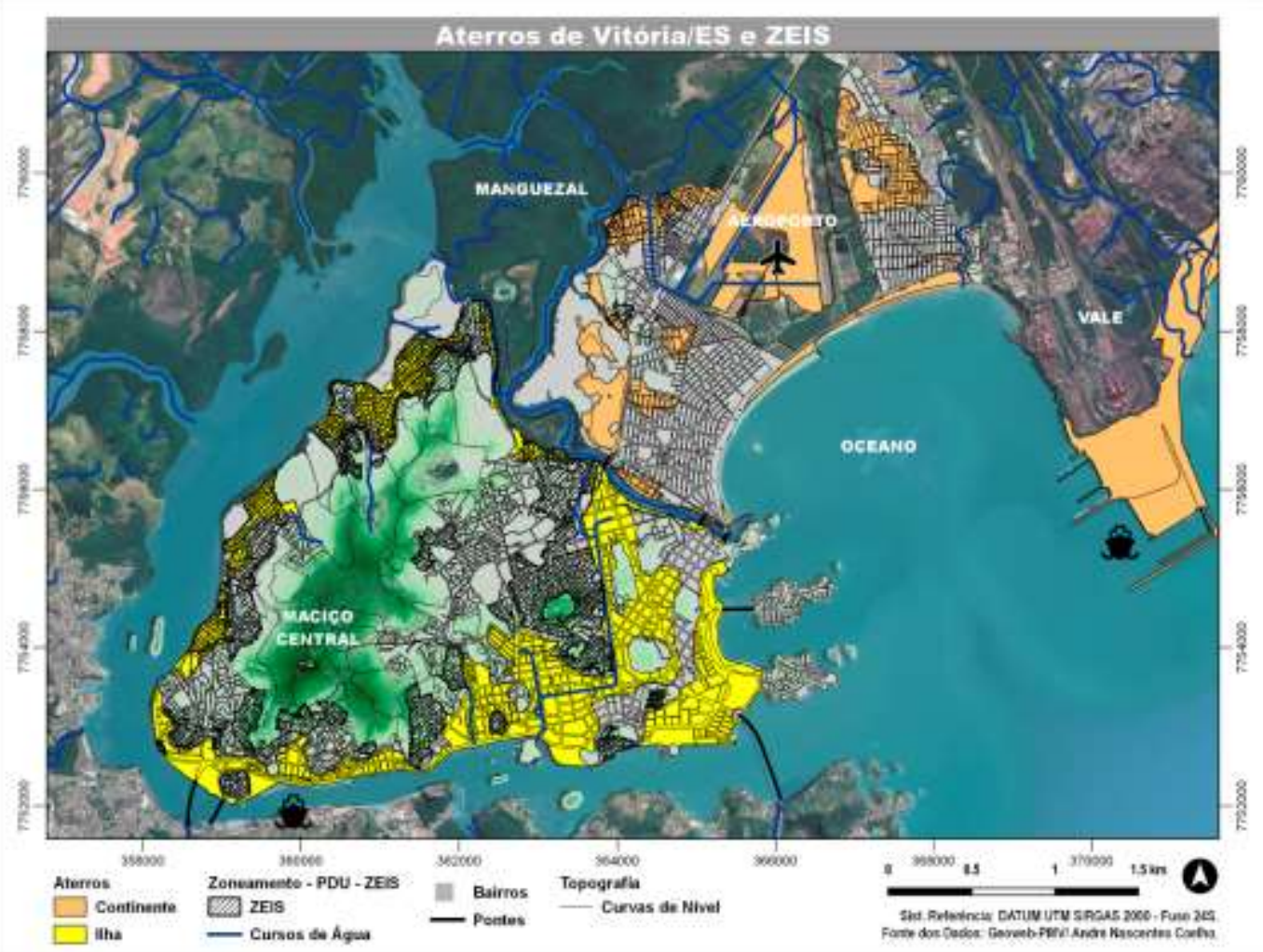


Entre as décadas de 1960 e 1980, a configuração espacial da Região Metropolitana da Grande Vitória sofreu mudanças, com sua malha urbana praticamente redesenhada. Segundo o IJSN (2011a), os processos econômicos iniciados na década de 1970 tiveram grande impacto na ocupação do território capixaba. A instalação dos Grandes Projetos - Companhia Vale do Rio Doce (CVRD), Companhia Siderúrgica de Tubarão (CST), Aracruz Celulose e Samarco Mineração - acarretaram significativo crescimento populacional e fluxos migratórios em Vitória, com uma intensa busca de empregos.

A política neoliberal em franca expansão aprofundou a desigualdade socioeconômica que se espacializou nas cidades do país. O neoliberalismo se afirmou gradativamente como projeto hegemônico na década de 1980 e tem como propósito legitimar ideologicamente o mercado. Na América do Sul os princípios neoliberais têm como diretrizes principais a redefinição do papel do Estado; a desconstrução das políticas desenvolvimentistas e da soberania nacional. Objetiva ainda a mercantilização de todas as áreas da vida social; a redução do custo da força de trabalho; a expropriação de direitos e políticas sociais da classe trabalhadora; a transformação do emprego em trabalho e da sociedade em negócio (FARIA; CHAIA, 2020).

Em Vitória o processo de espacialização da desigualdade socioeconômica não foi diferente. 0 Instituto de apoio à pesquisa e ao desenvolvimento Jones dos Santos Neves (IPES, 2001) afirma que na década de 1980 se iniciou um dos mais intensos processos de invasão de terras ocorridos na Grande Vitória, comprometendo áreas de extrema fragilidade ambiental. Em Vitória, deu-se a ocupação da área de manguezal na porção noroeste da cidade. Esta área, rejeitada pelo mercado imobiliário, bem como áreas de morros e encostas, tornaram-se alternativa habitacional para os migrantes pobres, desempregados ou em situação de subemprego, que chegavam no período à Vitória. Esse processo de intenso crescimento econômico reforçou as desigualdades sociais e a segregação espacial do território, provocando uma ocupação maciça em áreas periféricas e uma série de problemas de cunho socioambiental e humanitário.

Diante desse cenário, a gestão municipal criou, em 1996, o "Programa Integrado de Desenvolvimento Social, Urbano e de Preservação Ambiental em Áreas Ocupadas por População de Baixa Renda do Município de Vitória", denominado de Projeto Terra. 0 Programa é uma iniciativa de gestão pública para o enfrentamento da pobreza urbana, através de ações que visam promover a inclusão socioterritorial e o desenvolvimento humano sustentável (PMV, 2014).

A abrangência do Projeto Terra compreende 15 poligonais situadas em 33 bairros e 12 comunidades (Figura 2), atendendo à uma população de cerca de 85 mil habitantes, localizadas essencialmente na porção noroeste e norte da cidade, bem como sobre as áreas de morros e mangues (PMV, 2014). 0 referido Programa reforça objetivos que mais tarde seriam incorporados à política urbana nacional através da criação das Zonas Especiais de Interesse Social (ZEIS), com ações de enfrentamento aos problemas de natureza fundiária, infraestrutural, assim como, a provisão de moradias. Muitas dessas poligonais sobrepõem-se aos denominados Aglomerados Subnormais e às ZEIS, definidas pela primeira vez no município, através do Plano Diretor Urbano de 2006. 
Figura 2. Mapa de Aglomerados Subnormais e Poligonais do Terra, Vitória/ES.

Fonte: Os autores, 2020.

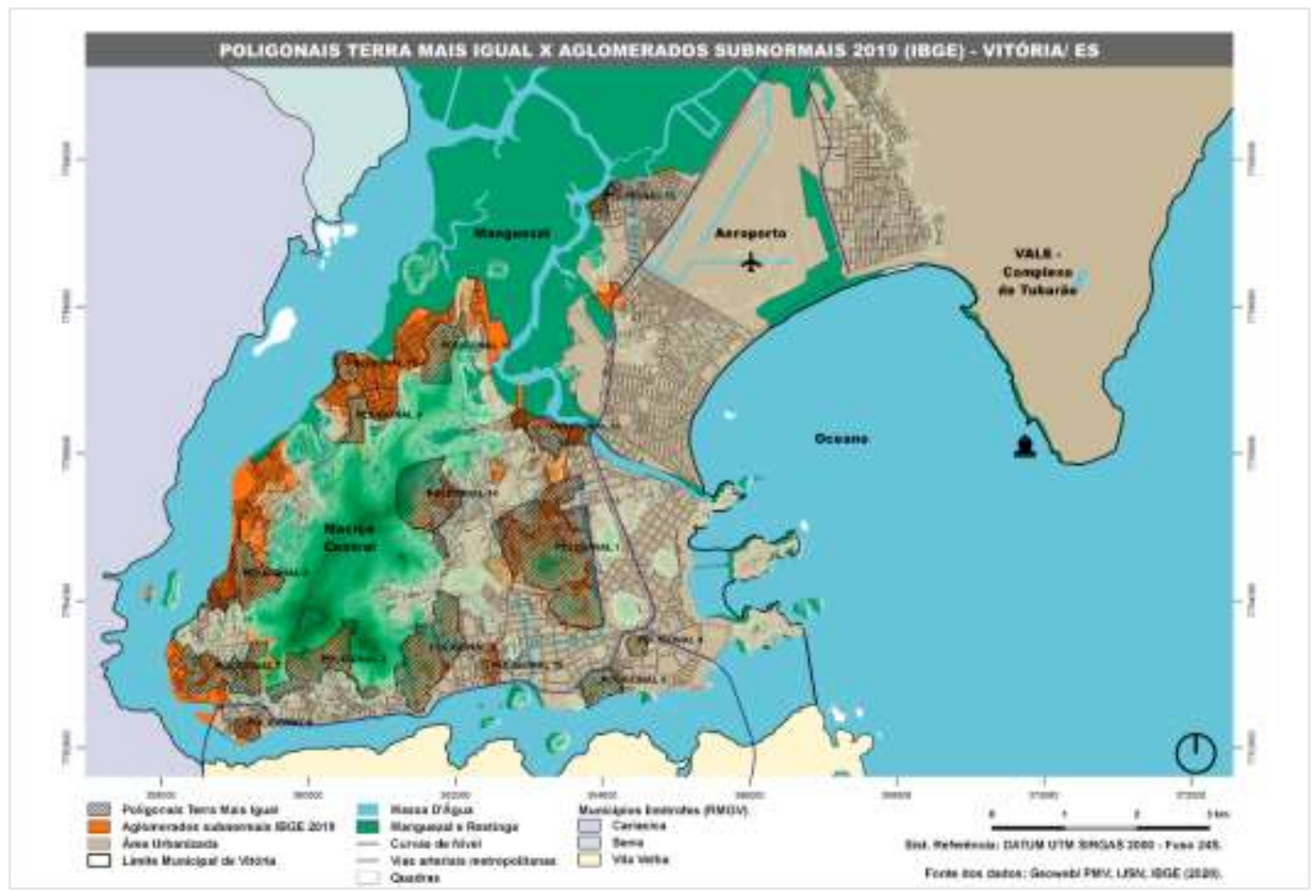

Entretanto, há um efeito nocivo ao bem-estar social gerado pelo desenvolvimento econômico no Estado e na capital que se agravou durante a pandemia. Uma pesquisa recente do IBGE (2020) atualizou o número de Aglomerados Subnormais no Brasil. A pesquisa foi destinada a subsidiar a instalação de Centros de Comunitários de Referência para o enfrentamento à COVID-19 no Âmbito da Atenção Primária à Saúde (APS), bem como, repassar subsídios financeiros às comunidades e favelas nesse momento da pandemia. 0 levantamento objetiva fornecer um parâmetro atualizado do tamanho dos aglomerados para fins de políticas de saúde, com dados até dezembro de 2019.

Estas ocupações situadas em aglomerados subnormais possuem problemas como: população com condições socioeconômicas, de saneamento e de moradia precárias, algumas com densidade domiciliar elevada, facilitando a disseminação da COVID-19. Vitória possui 34.393 domicílios situados em Aglomerados Subnormais, o que equivale a 33,16\% das unidades residenciais da capital, sendo um alto índice. Ressaltamos que em Vitória existem 14 aglomerados subnormais, conforme apresentado na figura 02 .

Observa-se, pelos dados apresentados, que os problemas identificados nas periferias de Vitória têm raízes históricas e são comuns às áreas idênticas pelo país afora com alto índice de população em situação de vulnerabilidade social. Uma breve análise socioeconômica de Vitória aponta que, em 2010, havia 33\% de moradores com renda familiar mensal de até três salários mínimos, sendo 7,2\% na faixa até um salário mínimo (IBGE, 2010).

No que tange à análise do comportamento do coronavírus no município de Vitória, bem como à elaboração de mapas temáticos, é importante ressaltar que o campo da arquitetura e urbanismo muito tem a contribuir com políticas públicas no combate às endemias, epidemias e pandemias. A COVID-19 expõe as mazelas das cidades no planeta: bairros e moradias com grandes aglomerações, falta de infraestrutura urbana, ausência de espaços públicos e de tratamento de lixo. Destacam-se, ainda, a mobilidade urbana não inclusiva, a poluição e a 
degradação ambiental, desafios não só para o planejamento das cidades, como para a saúde humana.

Ademais, é necessário reconhecer que os problemas de saúde urbana, condição que relaciona a saúde dos cidadãos e as disfunções de saúde das cidades, são decorrentes do desequilíbrio do ecossistema urbano, reforçado por problemas socioambientais, poluição, adensamento excessivo, imobilidade urbana, desigualdade socioambiental, doenças hídricas, dentre outras (SALDIVA, 2018).

As comorbidades dos indivíduos diagnosticados com coronavírus apontam as consequências da vulnerabilidade. Segundo Dow (1992), a vulnerabilidade pode ser compreendida enquanto resultado da exposição ou como uma medida das habilidades de enfrentamento aos riscos. Essa capacidade de administrar eventos, ameaças e mudanças ambientais é, portanto, assimétrica diante das desigualdades socioeconômicas, com maior probabilidade de atingir indivíduos pobres gerando efeitos nocivos em grau mais elevado e de difícil reversão e recuperação. Dow (1992), sugere uma correspondência entre as dimensões biofísica e social da vulnerabilidade: pessoas mais vulneráveis vivem em regiões equivalentes. Dada a diversidade de circunstâncias em que as pessoas vivem, é necessário um mosaico mais refinado de condições relevantes para a tomada de decisões.

\section{METODOLOGIA}

A metodologia empregada neste trabalho compreende a coleta e a manipulação de dados abertos referentes à pandemia de COVID-19 para o município de Vitória, considerando um recorte temporal entre abril e setembro de 2020, período de monitoramento da doença. Foram extraídas informações específicas que permitem a correlação entre saúde urbana, adoecimento e mortalidade pelo coronavírus. O Painel Covid-19 ES (ESPÍRITO SANTO, 2020) forneceu o documento base para o desenvolvimento do trabalho, através da planilha .csv disponível para download, com os dados detalhados de cada paciente contaminado com informações provenientes da base do Sistema Único de Saúde (SUS). Para proceder um diagnóstico apurado sobre as correlações socioespaciais da doença e da vulnerabilidade socioeconômica e precariedade urbana, foram coletados outros dados sobre demografia, renda, zoneamento urbanístico com ênfase em ZEIS, saneamento e outros.

Na sequência, as informações receberam tratamento estatístico para a elaboração de mapas georreferenciados no software QGIS, programa dedicado ao Sistema de Informação Geográfica, livre e aberto. Os mapas temáticos adotam uma forma de linguagem gráfica diagramática que permite o conhecimento da realidade conforme critérios traduzidos em simbologia espacial lógica e de fácil assimilação.

Desse modo, foram elaboradas duas categorias de mapas principais. A primeira categoria constitui-se de: i. mapas de símbolos proporcionais, de modo a exibir a intensidade dos eventos em cada bairro e ainda sobrepor outros atributos que qualificam as interpretações especializadas. A segunda categoria constitui-se de: ii. mapas graduados, categorizados por classes e organizados por cores que funcionam como indicadores numéricos para os eventos descritos, de modo a facilitar a identificação de distintos graus de intensidade, altos e baixos, e comparativos entre localidades e bairros.

Os mapas apresentam um mosaico de informações em contexto municipal e por bairros, acerca dos contaminados e dos óbitos pela Covid-19. Informam também, por bairro, a taxa de letalidade, a renda familiar mensal predominante, as comorbidades (doenças cardiovasculares, diabetes, cardiopatias, tabagismo, enfermidades pulmonares e obesidade), o atendimento da rede tratamento de esgoto, áreas de precariedade urbanística (ZEIS, aglomerados subnormais e Poligonais do Terra Mais Igual). 


\section{RESULTADOS}

\section{COVID-19 - CONTAMINADOS, ÓBITOS E LETALIDADE}

O ponto de partida para a compreensão do fenômeno de coronavírusii no município de Vitória envolve a identificação dos primeiros vetores de disseminação da doença, em seu estágio inicial. 0 primeiro mapa desenvolvido, remonta o mês de abril de 2020, momento em que os focos de contágio se situavam na porção leste da ilha e do continente de Vitória. Esse é o lócus de concentração de riqueza, compreende a faixa litorânea, com a exuberância da beira-mar, fruto de um processo de planejamento e expansão residencial e de serviços, com edifícios multifamiliares verticais, abundância de área de lazer, espaços públicos e infraestrutura qualificada.

Percebe-se o início dos vetores de expansão da Covid-19 na direção centro-noroeste, nas áreas de morro e dos bairros adjacentes ao manguezal. 0 mapa do dia 11 de abril (Figura 3) demonstra o estágio inicial de disseminação da doença no território, ilustrando de forma clara a concentração da enfermidade na porção leste, com áreas de morro ainda pouco impactadas pela contaminação. Dos 80 bairros do município de Vitória, apenas 33 contam com ao menos um caso, sendo Jardim Camburi o mais afetado, com 48 ocorrências. Todos os bairros com mais de 05 casos são de classes de renda alta, e a maioria das 15 Poligonais do Projeto Terra ainda não havia sido afetada ou dispunham de apenas 01 caso.

Figura 3. Mapa de Ocorrências de casos de COVID-19 por bairros de Vitória/ES em abril de 2020.

Fonte: Os autores, 2020.

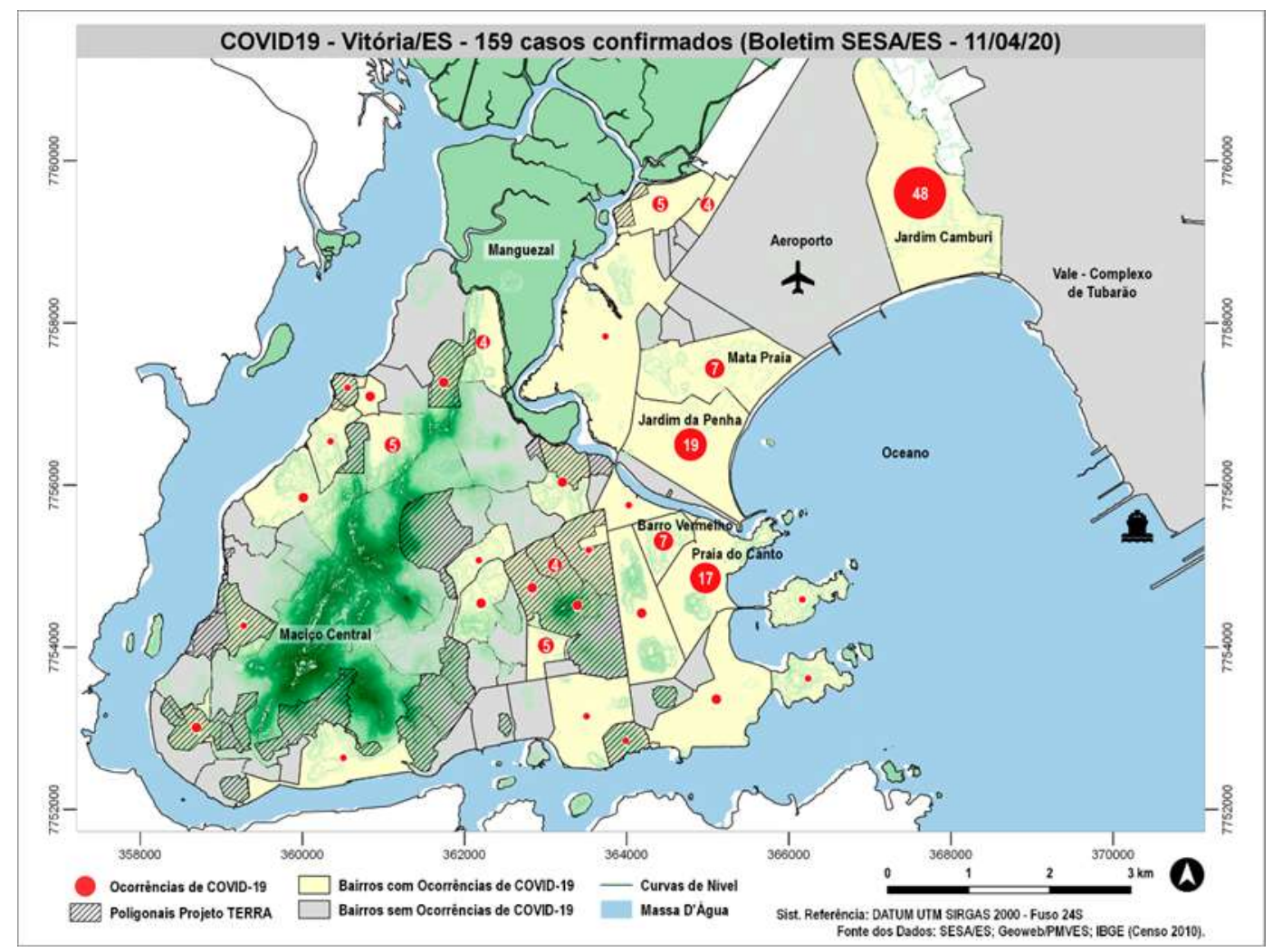

Na segunda transcrição (Figura 4), de 25 de maio de 2020, o território da cidade de Vitória já se apresenta completamente tomado pela COVID-19. O número total de ocorrências aproxima-se de 2.000 casos. Sobrepondo-se a quantidade de casos por bairro e a classificação 
destes por faixa de renda, é possível afirmar que, embora aqueles de renda média e alta como Jardim Camburi, Jardim da Penha, Mata da Praia e Praia do Canto (porção leste) apresentem maior número de infectados individualmente, o município foi afetado significativamente pela contaminação em bairros com proventos inferiores a cinco salários mínimos. Observou-se o acréscimo de ocorrências da doença em bairros mais pobres.

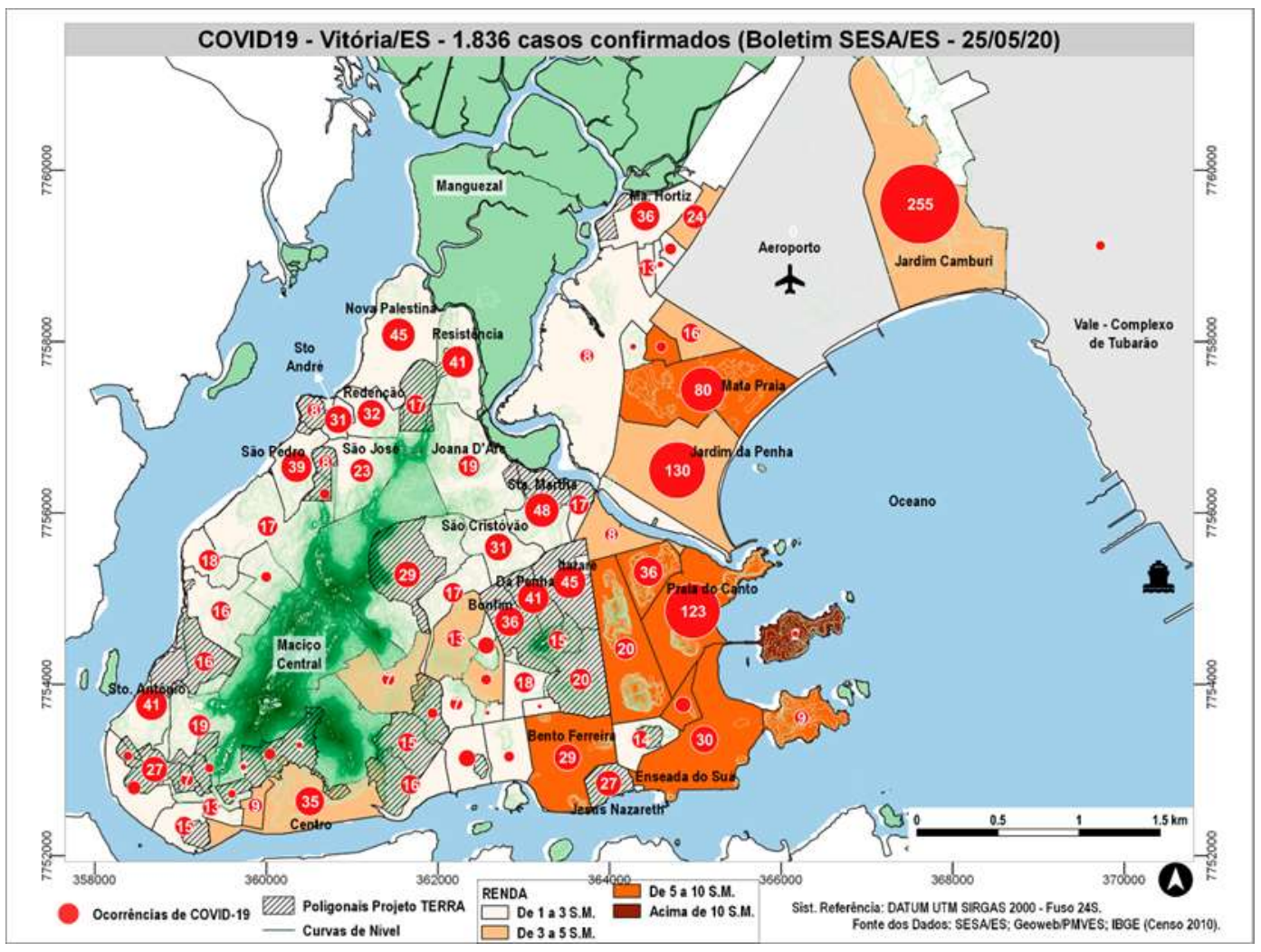

0 mapa de proporção de casos confirmados e óbitos por COVID-19, de 24 de setembro de 2020 (Figura 5), compreende um momento de estabilização da doença, com a matriz municipal de risco baixo, com o total de 15.181 casos e 430 mortes. A sobreposição dos dados de renda familiar mensal por bairro indica que aqueles da porção leste, também os mais populosos, como Jardim Camburi, Jardim da Penha, Praia do Canto e Mata da Praia, lideram a quantidade de infectados. Entretanto, a estratificação por renda aponta que os bairros que acumulam a renda salarial mensal de até três salários mínimos computam 53\% dos infectados.
Figura 4. Mapa de Ocorrências de casos de COVID-19 por bairros de Vitória/ES em maio de 2020.

Fonte: Os autores, 2020. 
Figura 5. Mapa de Ocorrências de casos e óbitos por COVID19 por bairros de Vitória/ES em setembro de 2020

Fonte: Os autores, 2020.

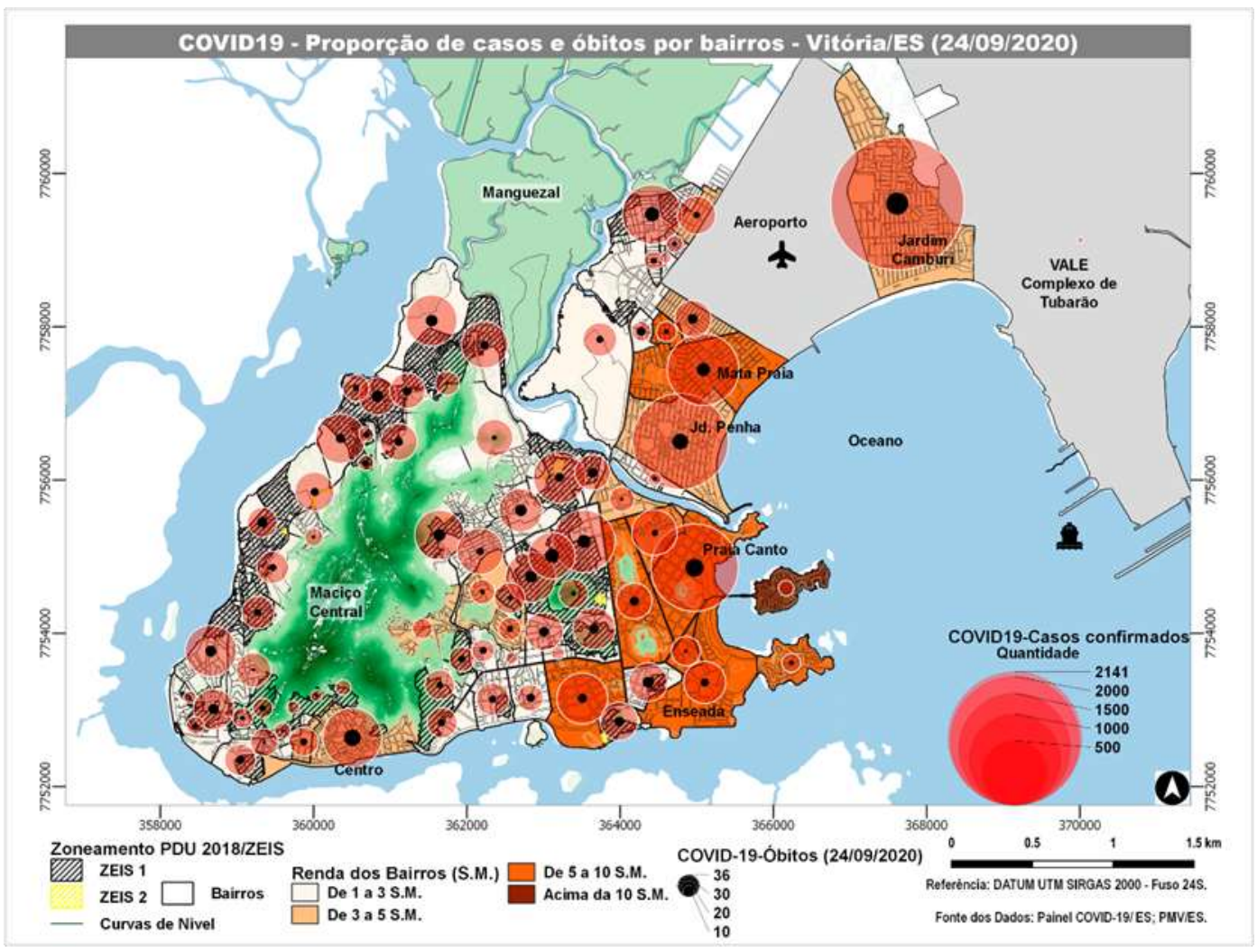

Os dados que melhor demonstram o grau de mortalidade em bairros de renda baixa são os percentuais de óbitos por classes de renda, com a seguinte composição: 63,48\% de óbitos em moradores residentes em bairros de renda entre zero a três salários mínimos mensais (s.m.); $22,09 \%$ de óbitos entre os residentes em bairros com renda entre três a cinco s.m.; $14,41 \%$ de óbitos entre os residentes de bairros com renda cinco a dez salários mínimos e nenhum óbito em bairro de renda acima de dez salários mínimos.

Esse é um dado determinante para a comprovação da "cruel pedagogia do vírus", expressão cunhada pelo sociólogo Boaventura de Sousa Santos (2020) para se referir ao papel do coronavírus no agravamento cruel das desigualdades e discriminações de que são feitas as cidades contemporâneas. Para o autor (SANTOS, 2020, p. 28) as "[...] pandemias mostram de maneira cruel como o capitalismo neoliberal incapacitou o Estado para responder às emergências". As respostas dadas à crise pelos Estados são variadas, mas, não omitem e disfarçam a sua incapacidade em relação às contingências.

As lições do vírus refletem o que Santos (2020) denomina de condição discriminatória da quarentena, mais difícil para determinados grupos sociais que compõem o "Sul" e impossível para outros. Santos (2020), se apropria da metáfora do "Sul", do distanciamento que não compõe um espaço-tempo geográfico, mas um espaço-tempo político, social e cultural, representativo do sofrimento humano injusto causado pela exploração capitalista.

Tal exploração se agravou, notadamente, a partir da década de 1940 com a atuação do economista austríaco Friedrich August von Hayek (1899-1992) e seus seguidores. Os economistas, sob os ideais neoliberais, passaram a defender a legitimação e hegemonia do capitalismo desregulamentado e o combate ao Estado de Bem-Estar Social. Nesta perspectiva, o ideal neoliberal defende que "[...] o princípio da igualdade é injusto e que a desigualdade encerra em si um caráter de justiça conferido pelo merecimento. [...] 0 compromisso real do neoliberalismo é com os interesses do grande capital" (FARIA; CHAIA, 2020, p. 1076). A 
concepção de democracia na acepção neoliberal resguarda os interesses das elites econômicas em detrimento "[...] daqueles que somente possuem a sua força de trabalho, para, assim, manter a dinâmica de acumulação e de reprodução do capital" (FARIA; CHAIA, 2020, p. 1076). Na crise pandêmica, no contexto neoliberal, conforme afirma Santos (2020), contatouse que os serviços nacionais de saúde dos Estados não estavam preparados para atender os cidadãos mais vulneráveis. Os Estados deveriam tomar medidas eficazes para evitar a propagação do vírus, mas, muitos deles, não possuem capacidade efetiva para responderem à crise humanitária em curso.

Nesse sentido, os moradores das periferias pobres e das áreas precárias vivem em espaços desurbanizados, pois "[...] habitam a cidade sem direito à cidade" (SANTOS, 2020, p. 18), com emergências sanitárias que se somam às muitas outras de caráter urbanístico e social. 0 direito à cidade é considerado aqui como um direito básico do cidadão, de acesso à vida digna, à cidadania, à moradia e à habitação, ao transporte, ao lazer, aos equipamentos de uso social e comunitário, às oportunidades de emprego, educação e saúde. Representa, como afirma Tavolari (2016), mais do que um direito institucionalizado na forma de lei, mas sobretudo de direitos humanos, de igualdade, democracia e justiça social.

0 município de Vitória, na ocasião da construção do mapa de letalidade (Figura 6), em 24 de setembro de 2020, apresentava uma taxa de letalidade média de 2,7\%, mas a análise apurada por bairros permite melhor compreensão desta distribuição. 0 bairro de Jardim Camburi, embora esteja no ranking de casos confirmados (2141) e óbitos (36), apresenta uma Taxa de Letalidade bem abaixo da média municipal, com 1,59\%. Esse quadro se mantém nos bairros nobres da cidade, com situações excepcionais como o Aeroporto, que informa duas mortes em três casos, o que não representa um registro coerente visto que não contém unidades domiciliares. Vale destacar que, de todos os 26 bairros com a letalidade acima de 4\%, há apenas dois que não configuram bairros de baixa rendaii. Percebe-se, portanto, que a letalidade nos bairros nobres permanece baixa desde o início do monitoramento.

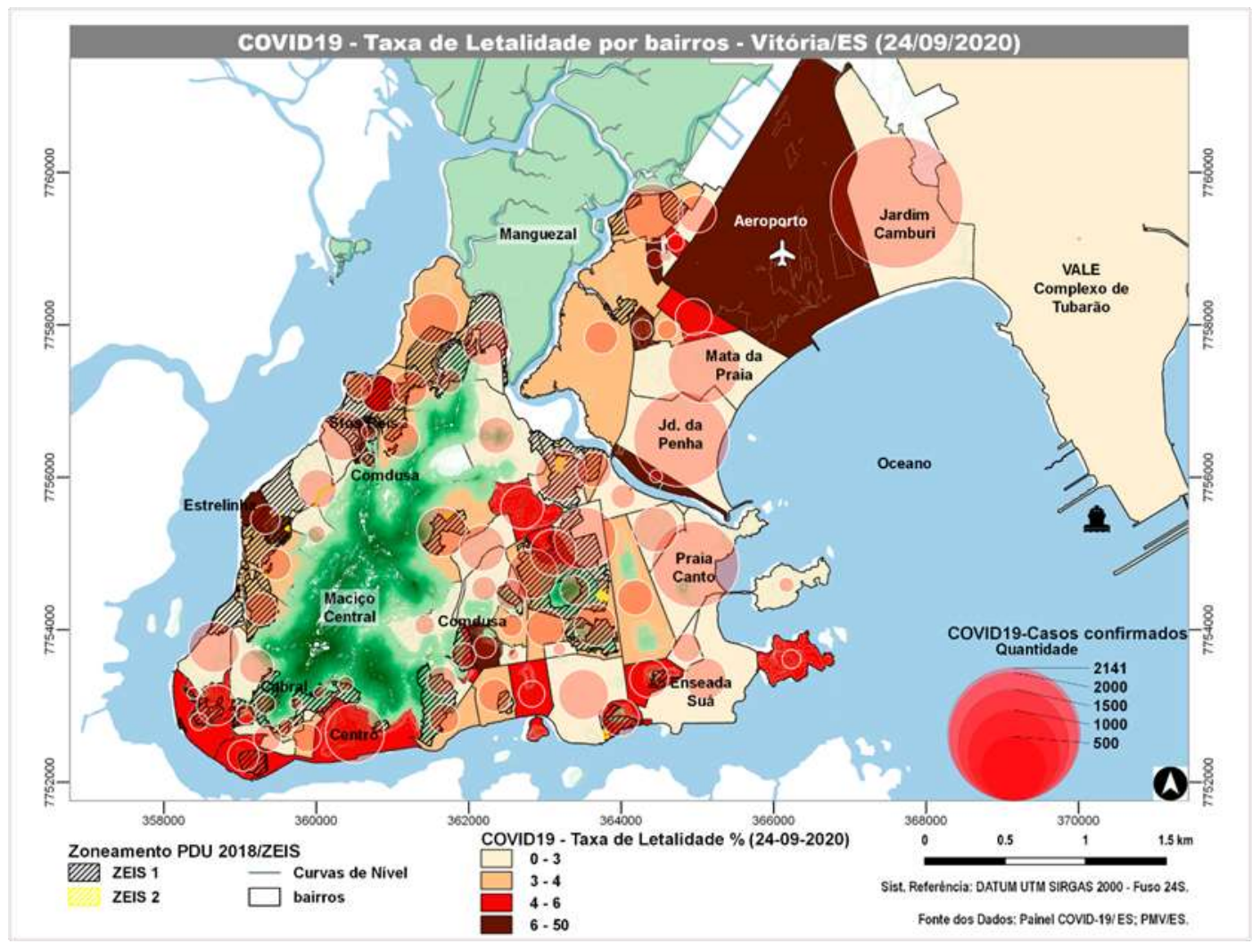

Figura 6. Mapa da Taxa de Letalidade por COVID-19 em Vitória/ES, em setembro de 2020.

Fonte: Os autores, 2020. 


\section{COVID-19 - COMORBIDADES}

A comorbidade é um termo da área médica, utilizado quando há duas ou mais doenças etiologicamente relacionadas. No caso da COVID-19, é imprescindível diagnosticar doenças preexistentes, fatores de risco e vulnerabilidade. A espacialização das comorbidades dos infectados pela COVID-19 em Vitória foi tratada de forma a se obter a taxa percentual por bairros. A partir de então estabeleceu-se a relação de proporção entre cada categoria de comorbidade pelo número de infectados em cada bairro, compondo uma taxa que permite uma comparação entre os mesmos.

Os mapas receberam uma camada de sobreposição dos limites das ZEIS para reforçar e localizar as áreas de precariedade urbanística e o grau de comorbidade que abrange esses recortes territoriais. Este cruzamento auxilia na interpretação dos dados. Sabe-se que a saúde e a qualidade de vida urbana possuem relações estreitas com a localização da moradia, com a infraestrutura de saneamento, com as condições de vida, com a qualidade dos alojamentos, hábitos, renda, boa alimentação e nutrição, deslocamento, oferta de áreas verdes e espaços públicos, serviços e equipamentos comunitários.

0 primeiro mapa de comorbidades informa a taxa de obesidade dos contaminados (Figura 7). Percebe-se que o tecido planejado leste e os bairros do continente litorâneo, de maior poder aquisitivo, dispõem de baixas taxas de obesidade, inferiores a $4 \%$. Complementarmente, o mapa aponta uma oferta ampla de espaços livres de uso público nestes lugares. Há presença de parques abertos à população, praças e extensas orlas urbanizadas com numerosos equipamentos para a prática de esportes, ciclovias, calçadão de caminhada, áreas de lazer e recreação. Entretanto, há uma condição desigual na distribuição dos espaços públicos na cidade, pois, os bairros localizados nos morros e nas franjas noroeste possuem poucos fragmentos à disposição dos moradores. Essa é uma das contradições da geomorfologia da ilha de Vitória, que dispõe de vastas áreas de Preservação Ambiental, como o Maciço Central onipresente, com mata atlântica de encosta no coração da cidade, com 1.100,00 hectares. Entretanto, a área do Maciço Central não desempenha papel relevante nas práticas cotidianas de esporte e lazer. Portanto, não é de usufruto habitual das comunidades do entorno situadas adjacentes ao anel viário que o contorna. 


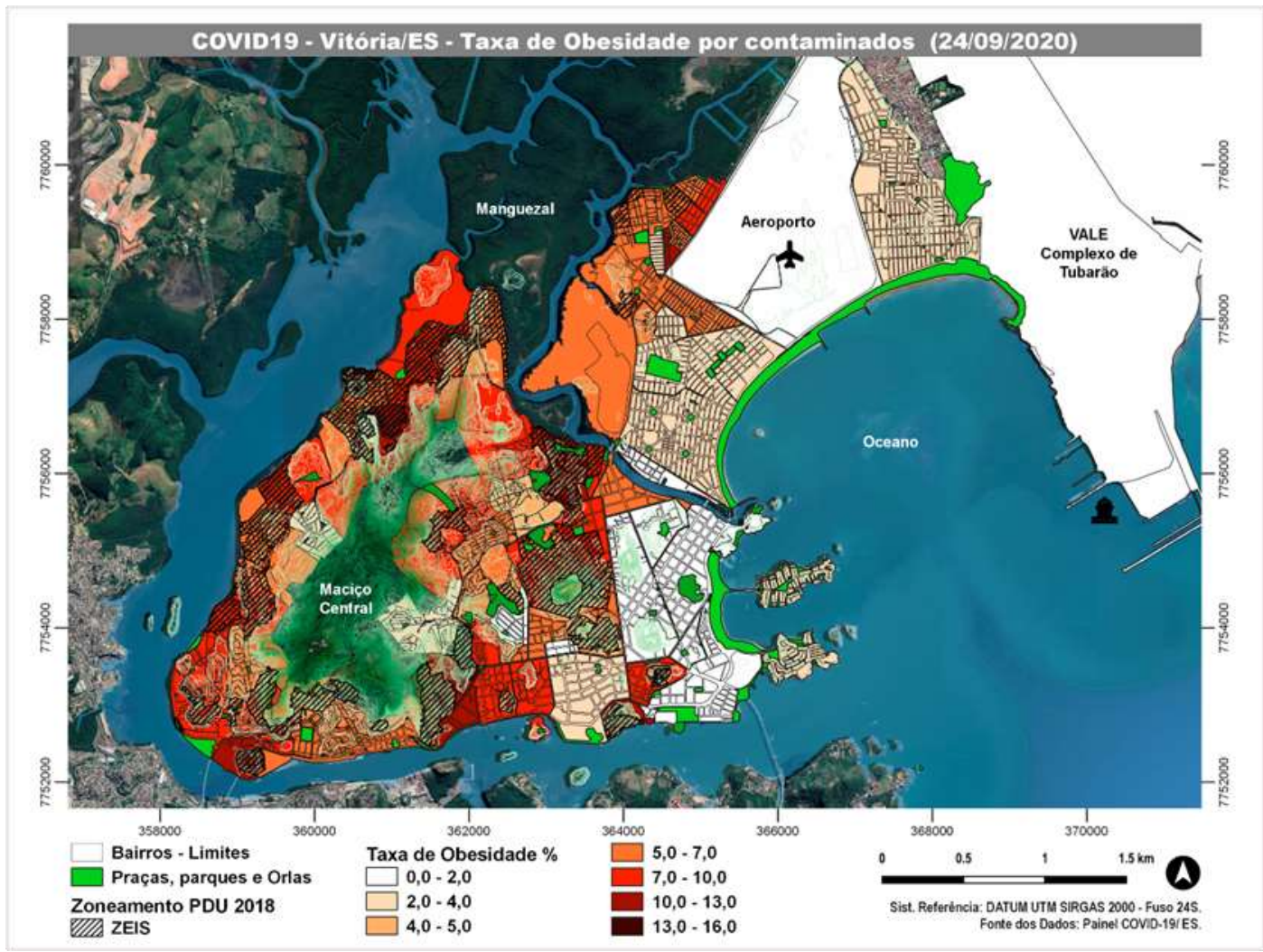

Outro aspecto relevante refere-se à dicotomia entre os indicadores de qualidade atribuídos à cidade de Vitória, que obteve a primeira colocação no ranking de Saúde, na plataforma Connected Smart Cities Edição 2020 (URBAN SYSTEM, 2020) e a pesquisa Vigitel (BRASIL, 2020a). A plataforma Connected Smart Cities é destinada ao mapeamento das cidades com maior potencial de desenvolvimento no Brasil e a outras investigações de saúde urbana, enquanto a pesquisa da Vigilância de Fatores de Risco e Proteção para Doenças Crônicas por Inquérito Telefônico Vigitel (BRASIL, 2020a), avalia fatores de risco como "[...] o hábito de fumar, o excesso de peso, o consumo de refrigerantes, de alimentos ultraprocessados, a inatividade física e o consumo de bebidas alcoólicas, além da referência ao diagnóstico médico de hipertensão arterial e diabetes" (BRASIL, 2020a, p.19).

A pesquisa Vigitel (BRASIL, 2020a) se propõe a investigar os problemas de saúde pública, em especial as doenças crônicas não transmissíveis (DCNT), que possuem múltiplas causas de origem física, social, econômica e ambiental, ou seja, apresentam correlação direta com o ambiente urbano. Segundo os dados da Vigitel (BRASIL, 2020a), a frequência de adultos com excesso de peso no município de Vitória compreende $49.1 \%$ e a obesidade situa-se em torno de 17,6\%. A condição nutricional aponta o consumo regular de frutas e hortaliças por apenas $39,7 \%$ da população. A prática de atividade física no tempo livre compreende $44,2 \%$ da população, com $13,7 \%$ de recorrência considerando-se as atividades físicas ao longo de deslocamentos cotidianos. A prática insuficiente de atividade física compreende $42 \%$ de adultos; e o consumo de tempo livre com o uso de televisores e dispositivos móveis equivale a $65,3 \%$.

O mapa das taxas de doenças cardiovasculares (Figura 8) por bairro demonstra que as baixas incidências situam-se na porção leste da ilha e do continente, correspondente aos bairros dotados de melhor infraestrutura. A análise apurada dos dados aponta que, dos 21 bairros de Vitória com taxa de cardiopatia abaixo de $20 \%$, há apenas 4 com renda de até três salários
Figura 7. Mapa da Taxa de obesidade entre contaminados por COVID-19 em Vitória/ES.

Fonte: Os autores, 2020. 
mínimos. Todos os bairros de renda média e alta situam-se nesta classificação. Não há nenhum bairro com renda média familiar mensal acima de cinco salários mínimos com taxa de doenças cardiovasculares acima de $20 \%$. No universo de 59 bairros com taxa superior a $20 \%$ apenas cinco destes apresentam renda entre três a cinco salários mínimos. Esse fato relaciona-se às premissas de Fajersztajn, Saldiva e Veras (2016), que afirmam que doenças cardiovasculares possuem relação direta com alimentação de baixa qualidade nutricional, baixo índice de áreas verdes, falta de exercício físico, obesidade, estresse mental, e poluição do ar.

Figura 8. Mapa da Taxa de doenças cardiovasculares entre contaminados por COVID-19 em Vitória/ES

Fonte: Os autores, 2020.

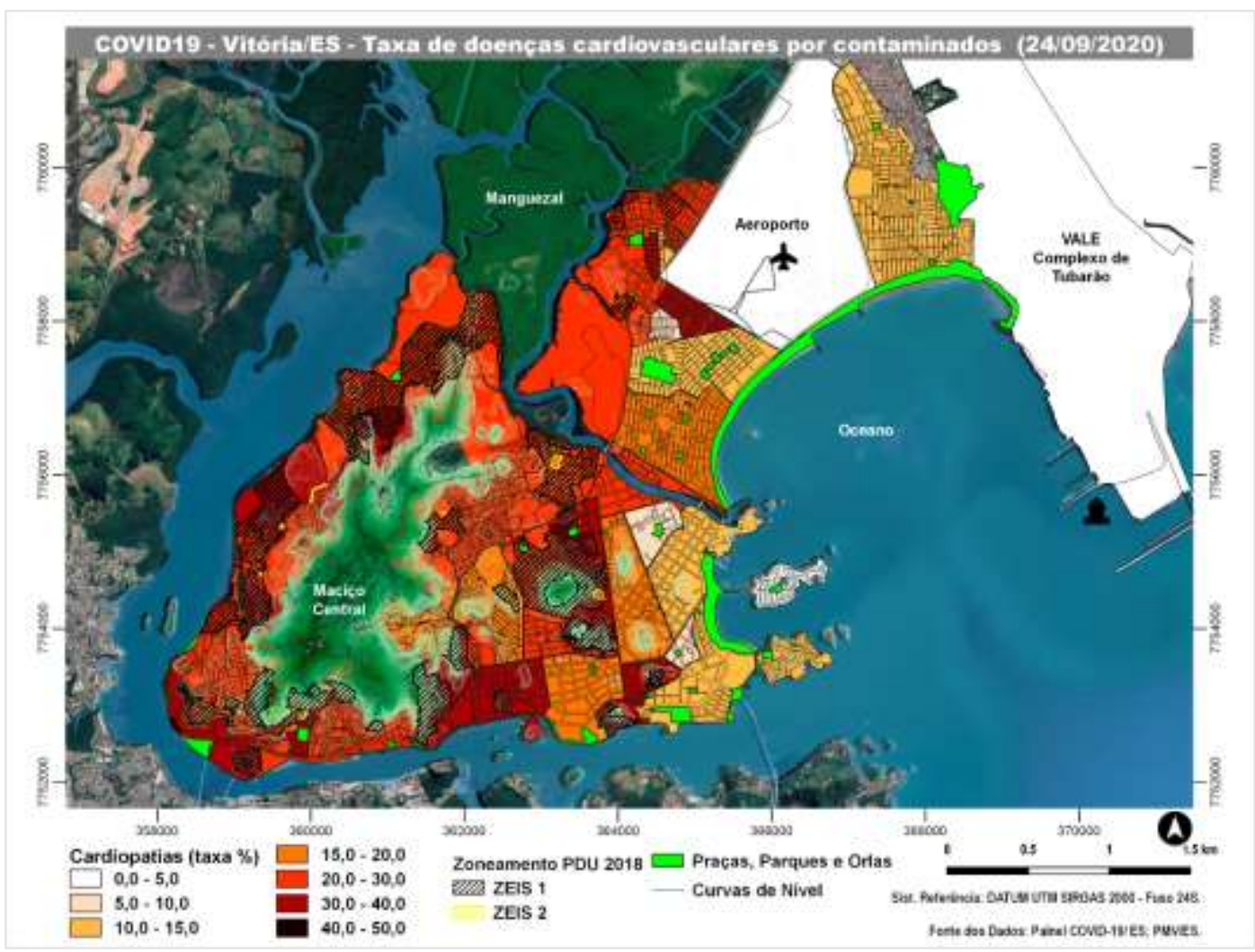

Contatou-se que a região noroeste de Vitória concentra os maiores percentuais de comorbidades e de óbitos causados pela COVID-19. Entre $20 \%$ e $51 \%$ dos pacientes no mundo com a COVID-19 foram detectados, até maio de 2020, com pelo menos uma doença crônica já instalada, condição que acelera um prognóstico pior na evolução da enfermidade causada pelo coronavírus (FEITOZA et al., 2020).

Muitas comorbidades possuem relação com a obesidade, que vem aumentando no Brasil desde 1974. A educação alimentar e nutricional (EAN) tem relação direta com a saúde dos obesos. 0 Brasil possui instrumentos legais que colocaram a EAN como uma das diretrizes da Política Nacional de Segurança Alimentar e Nutricional (PNSAN). A EAN tem relação direta com o tratamento das doenças infectocontagiosas (BRITO et al., 2017), logo, com a COVID-19.

O núcleo do BRCIDADES/Espírito Santo (2020) organizou, no âmbito das eleições municipais, 17 princípios norteadores da agenda nacional para as cidades capixabas; entre eles, o de segurança alimentar. Entre os principais pontos de pauta para a temática, destacam-se quatro: a reivindicação da elaboração de Planos de Segurança Alimentar; a revisão dos Planos 
Diretores, subsidiando a segurança alimentar, hídrica e energética; a indicação do uso de tecnologias permaculturais, agroecológicas e de outras escolas para a autossuficiência; e a implementação de políticas públicas que garantam a difusão de hortas urbanas agroecológicas. A agenda apresentou ainda a proposição de ações produtivas voltadas tanto para os espaços públicos quanto privados, e a viabilização do uso sociofuncional do espaço urbano ocioso (BRCIDADES, 2020).

No Brasil, o surgimento da COVID-19 explicitou as diferentes dimensões da Segurança Alimentar e Nutricional (SAN). Iniciativas e políticas para a garantia da SAN devem contemplar a articulação de medidas governamentais nas três esferas de gestão, visando assegurar o acesso à alimentação adequada e saudável, com vistas a reduzir os impactos negativos da doença na condição alimentícia, na saúde e nutrição dos mais vulneráveis (RIBEIRO-SILVA et al., 2020). No contexto pandêmico ações de gestão local e estadual devem contemplar a reorganização da agricultura familiar, que responde pela maior parte da produção de alimentos destinados ao consumo interno no Brasil (RIBEIRO-SILVA et al., 2020); o incentivo à implementação de hortas urbanas; e, o uso de tecnologias permaculturais.

No contexto da pandemia, as práticas agroecológicas estão sendo reforçadas através de ações solidárias, como as das equipes de pesquisa do Projeto AgroEcos (2020). A equipe possui pesquisadores de três países: Reino Unido, Bolívia e Brasil. Participam do projeto a Open University (OU), do Reino Unido; a Comunidad de Estudios Jaina (CEJ), da Bolívia; a Universidade Estadual Paulista (UNESP) e o Observatório dos Territórios Sustentáveis e Saudáveis da Bocaina (OTSS), ambas do Brasil. Os pesquisadores realizaram, no ano de 2020, seminários virtuais com o tema - Economia Solidária e Agroecologia enfrentam a pandemia de Covid-19. Além disso, veem elaborando, pesquisa-ação-participativa com organizações comunitárias que promovem inovação agroecológica. Estão incluídos no projeto, organizações camponesas, indígenas e de mulheres. Os territórios envolvidos são o Valle Central da Bolívia, Litoral Norte de São Paulo e Sul Fluminense e a Baixada Santista (SP) Serão, também, combinados, testados e refinados os métodos de pesquisa culturalmente fundamentados promovendo o diálogo de saberes; bem como, identificadas e fortalecidas as capacidades da comunidade para uma economia solidária baseada na agroecologia (AGROECOS, 2020).

Como forma de enfrentamento às restrições alimentares da COVID-19, práticas de agricultura urbana em assentamentos informais foram implementadas de forma dialogal com a comunidade de Suva, Fiji, com recursos do Fundo Global Emergencial da UN-Habitat e do Ministério da Habitação e Desenvolvimento Comunitário. A carência de espaços disponíveis para plantio e o problema do alagamento das terras foram contornados através do emprego de técnicas verticais de plantio em recipientes e contêineres. As famílias receberam capacitação para a execução das hortas, sementes e fertilizantes para o cultivo do próprio alimento, nutritivo e sem custo. A iniciativa promoveu o engajamento de 40 mil pessoas em 70 assentamentos informais, com técnicas de baixo custo e simplicidade de execução (UNHABITAT, 2020).

Experiências participativas imediatas de qualificação de espaços públicos no contexto da Covid-19 são incentivadas pela UN-Habitat, Agência das Nações Unidas para o desenvolvimento sustentável, em parceria com instituições, governos locais e comunidades. Intervenções em áreas de vulnerabilidade se destacam no Vietnã, Bangladesh, índia, e outros países do "Sul" global, objetivando descongestionar mercados locais, criar áreas verdes compartilhadas, espaços públicos de usos flexíveis, e ambientes saudáveis de uso cotidiano que evitem a propagação e a disseminação do vírus. Destacam-se o playground móvel para crianças em Hanói, Vietnã, para ser instalado em pequenos interstícios públicos; estruturas 
temporárias para vendedores ambulantes em Dhaka e Khulna, Bangladesh, voltada para abrigar, em áreas abertas, vendedores dos mercados públicos. Destacam-se, também, espaços públicos seguros em assentamentos informais de Bhopal, Índia, revertendo áreas abandonadas em assentamentos informais em espaços públicos equipados e sadios (HARROUK, 2020).

0 mapa das taxas de doenças pulmonares (Figura 9) sinaliza que, dos 44 bairros com taxas acima de 5\%, há apenas 7 destes com renda acima de três salários mínimos. Já dentre os 36 bairros com taxas abaixo de $5 \%$, há 15 destes com renda média e alta. De fato, as doenças pulmonares, no contexto municipal, podem ser avaliadas à luz de dois fatores essenciais: i. nível de poluição do ar, agradava pelo aumento acelerado da frota de automóveis e pelas altas emissões geradas pelas indústrias mineradoras e siderúrgicas, localizadas no extremo leste do continente, em que incide o vento nordeste que carrega as partículas em direção à mancha urbana; ii. relação entre a habitabilidade, precariedade, adensamento excessivo, insalubridade habitacional (ventilação e iluminação inadequadas, umidade, infiltrações, ausência de revestimentos e acabamentos), que potencializam e desencadeiam doenças como asma, bronquite, pneumonia, tuberculose e outras, em se tratando de áreas vulneráveis. Ainda que esse cenário equalize a distribuição das doenças pulmonares de forma a incidir também de maneira veemente em áreas nobres da cidade, as regiões precárias e de baixa renda concentram as maiores taxas.

Figura 9. Mapa da Taxa de doenças pulmonares entre contaminados por COVID19 em Vitória/ES.

Fonte: Os autores, 2020.

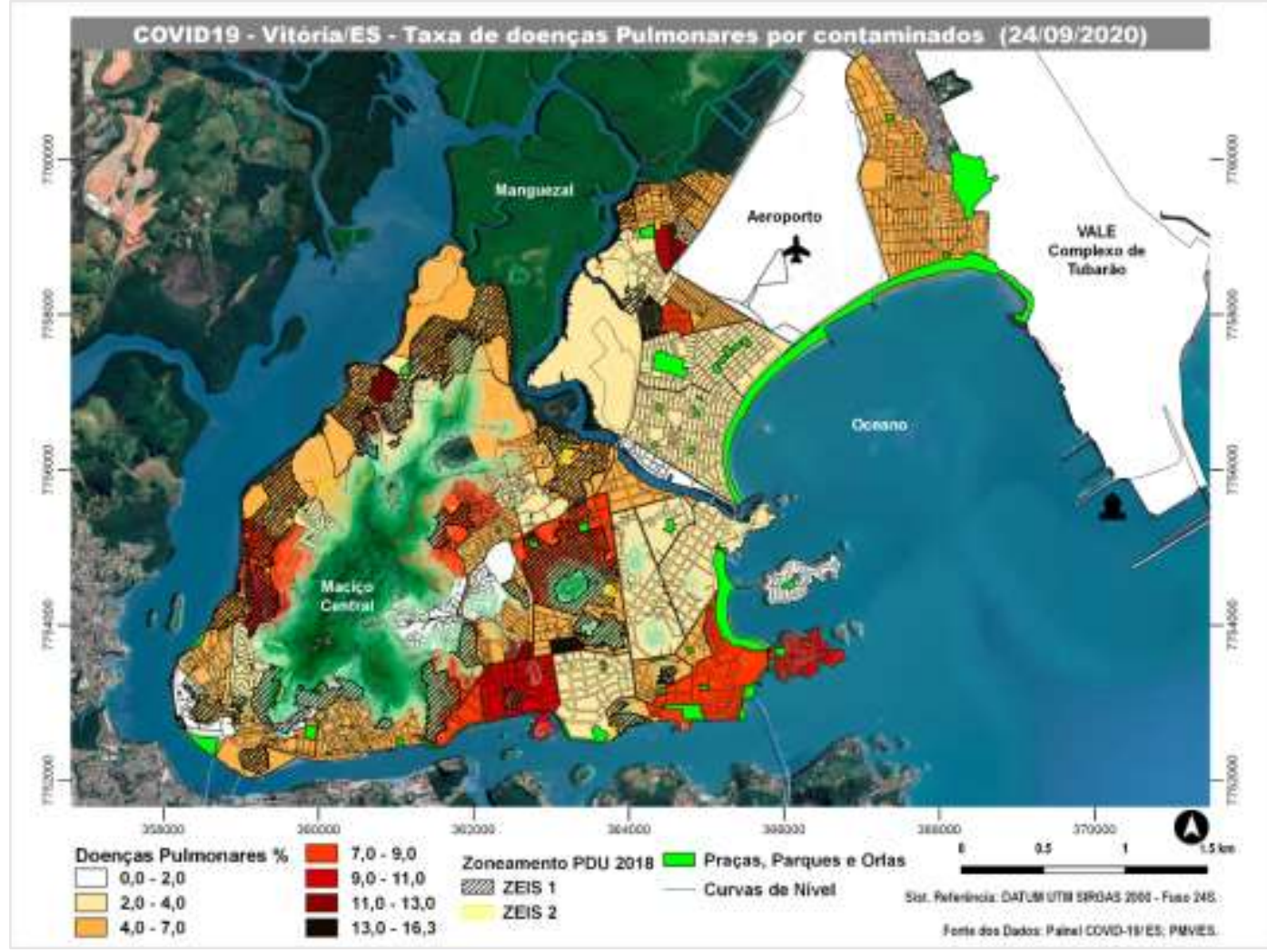

Aqui, é oportuna a reflexão sobre a qualidade do projeto habitacional no contexto de informalidade, considerando a inoperância do Estado em reverter o grau de precariedade das moradias e a concentração de investimentos públicos para a promoção de melhorias 
orientadas prioritariamente para aprimorar a infraestrutura urbana após o estabelecimento dos tecidos urbanos espontâneos. 0 projeto da moradia social, autoconstruída, concebida no âmbito da ilegalidade procedimental e profissional, é o modus operandi da informalidade, que rivaliza com os processos formais de subordinação à lógica do mercado habitacional, de concepção de produtos acabados, padronizados, que não atendem às necessidades familiares distintas. A lógica do mercado habitacional, em maior grau, exclui as famílias de baixa renda pela incapacidade destas de garantir recursos financeiros para a sua aquisição formal. Nesse sentido, destaca-se a relevância das Tecnologias Sociais compreendidas como quaisquer "[...] produtos, técnicas e metodologias reaplicáveis, desenvolvidas na interação com a comunidade e que representem efetivas soluções de transformação social" (KAPP; CARDOSO, 2013, p. 97). Do mesmo modo, evidencia-se a Assessoria Técnica em Arquitetura e Urbanismo que trabalha com grupos socioespaciais, de modo horizontal, colaborativo, com incentivo às ações coletivas, considerando demandas próprias, saberes, estimulando competências, interações, interfaces para a produção do espaço, processos autônomos, proatividade e participação comunitária efetiva (KAPP, 2018). Recomenda-se a revisão no processo de projeto, em todas as etapas, com base nas Tecnologias Sociais. Objetivamente, pode-se melhorar o ambiente construído através do incentivo às soluções tecnológicas que considerem a participação popular, o cooperativismo e a autonomia coletiva. Kapp e Cardoso (2013), alertam para a necessidade de estimular,

[...] processos construtivos cujas rédeas estejam nas mãos de quem realiza o trabalho material, como nas cooperativas de construção e em arranjos semelhantes, terão efeitos sociais duplos: por um lado, o atendimento de necessidades habitacionais pelos produtos da construção (moradias melhoradas ou moradias novas) e, por outro, o desenvolvimento social de trabalhadores com melhor qualificação, renda mais alta e experiência de organização coletiva (KAPP; CARDOSO, 2013, p. 101).

Entende-se que os impactos positivos na saúde habitacional, pelo fortalecimento de uma rede de tecnologias sociais, sejam determinantes para enfrentar o problema da moradia precária. É possível a materialização de habitações com maior qualidade, conforme necessidades habitacionais reais. Cita-se a inclusão de trabalho produtivo em associação ao espaço doméstico (espaços laborais, de serviços e cômodos autônomos). Ressalta-se o emprego de estratégias de flexibilidade arquitetônica como uso simultâneo do espaço, habitação evolutiva e expansível, cômodos autônomos (para coabitação ou atividades independentes de comércio e serviços), adequação ao ciclo de vida familiar e etário. Além disto, soluções de conforto ambiental, plenamente adequadas ao contexto local, resoluções formais e funcionais das unidades, para maior adequação às famílias monoparentais de chefias femininas.

No que tange às ações emergenciais, com o uso de tecnologias sociais durante a pandemia, cita-se a atuação do IAMÍ - Instituto de Assessoria à Mulheres e Inovação, em Belo Horizonte. $\mathrm{O}$ instituto foi criado pelas mulheres que executam o projeto Arquitetura na Periferia (AnP), oriundas da Escola de Arquitetura da UFMG. O AnP objetiva a melhoria da moradia para mulheres que residem em territórios com déficit de habitação e infraestrutura, através de capacitação para conhecimento de práticas e técnicas de projeto e planejamento de obras, objetivando a equidade de gênero e o combate às desigualdades sociais. Através de microfinanciamento, as beneficiadas, pessoas com baixo rendimento, podem conduzir com autonomia e sem desperdícios as reformas de suas casas. Durante o período da crise pandêmica a AnP continua capacitando mulheres através de oficinas on line e atuando como rede de apoio para amparar as beneficiadas em situação de vulnerabilidade com efetivas soluções de transformação social (ANP, 2021). 
Outra ação importante foi a adaptação do sistema modular argentino CAUH (Haus Arquitectura y construcción inteligente) para a construção da casa do Sr. Manoel, morador do autodenominado Território do Bem, localizado em Vitória/ES. A casa, concebida com peças em madeira, cortadas previamente e transportadas para o sítio, foi construída no bairro Consolação, onde há setores com domicílios rústicosiv. Estas habitações, por sua vulnerabilidade, causam doenças respiratórias crônicas. Uma pesquisa recente apontou que as doenças respiratórias são o segundo problema de saúde mais citado pela comunidade, depois da hipertensão, o que aumenta o risco de contaminação da SARS-CoV-2. O design do sistema modular CAUH possui fácil e rápida montagem, baixo custo, passível de autoconstrução e não requer mão de obra qualificada; representa um modelo replicável para outras habitações ou equipamentos públicos. Pode ser feita através de mutirão, mas, devido à pandemia, foi contratada mão de obra local. Esta ação resultou da parceria entre o Núcleo do BR Cidades do Espírito Santo, o Coletivo Beco e professores do Departamento de Arquitetura e Urbanismo da Universidade Federal do Espírito Santo (BENFEITORIA, 2020).

Outra iniciativa de relevância com atuação no Território do Bem, no município de Vitória, é o projeto Saúde Habitacional, que advém da parceria entre as ONGs Ateliê de Ideias, Onze8 e o Instituto Unimed Vitória. Desenvolve-se em uma das ZEIS mais populosas da capital, e promove melhorias no saneamento básico de unidades habitacionais precárias, e reversão das condições de inadequação e insalubridade habitacional (FILETTI, 2020).

Para discutir infraestrutura e saneamento, construiu-se o mapa de demonstração da quantidade de imóveis não conectados à rede de esgoto, em valores absolutos por bairro (Figura 10). Nesse caso, a fonte da informação é a planilha de dados abertos, disponível no Portal da Transparência da Companhia de Saneamento do Espírito Santo (CESAN), que informa o endereço de cada imóvel que não possui a referida ligação à rede. 0 município dispõe de um índice de cobertura de água potável de 100\%, com 96,7\% de atendimento. 0 índice de cobertura de esgoto é de $91,5 \%$, e atende a $83,1 \%$ da população. A espacialização desses imóveis que não estão conectados à rede reflete a persistência da carência de saneamento básico em bairros do centro-oeste da cidade. Coincide, também, com as áreas de irregularidade fundiária, ocupações em morros e bairros com menor renda familiar.

A ausência de saneamento básico e a precariedade infraestrutural são fatores determinantes para a disseminação de inúmeras doenças hídricas, tais como, diarreia, dengue, infecções intestinais, leptospirose, dentre outras. Nas comunidades onde há situações de insuficiência e/ou precariedade nos serviços de abastecimento de água existe o risco para a proliferação do SARS-CoV-2, o que aumenta os riscos da transmissão do novo coronavírus por alimentos contaminados (RIBEIRO-SILVA et al., 2020). 


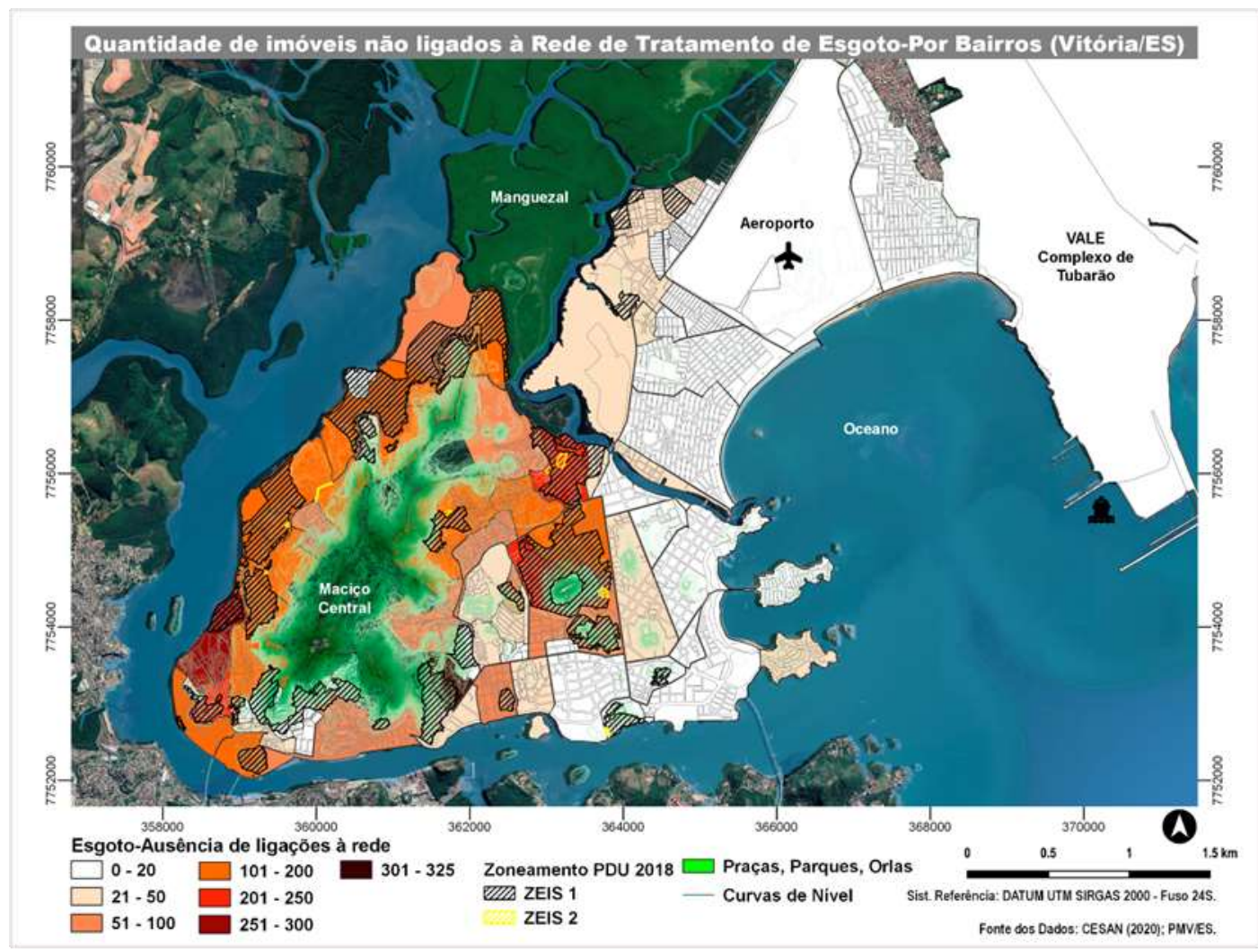

\section{CONSIDERAÇÕES FINAIS}

A pandemia do novo coronavírus demonstrou, através do mapeamento desenvolvido que, em Vitória, a desigualdade socioespacial elimina vidas dos corpos mais vulneráveis, seja em relação à doença, seja em referência à sobrevivência na pandemia. São pessoas que, historicamente habitam a cidade informal; compreende a população mais vulnerável e mais pobre, portadores de doenças oriundas da desigualdade socioeconômica, das más condições de vida e moradia, da carência de serviços urbanos e da falta de oportunidades.

A má distribuição de renda imprime suas consequências no espaço da cidade e sinaliza a necessidade definitiva de maior proteção do Estado. Esta proteção se dá através do fomento de ações integradas de promoção à saúde, geração de emprego e renda, políticas fundiárias, implementação de espaços públicos de qualidade com áreas de lazer ativo, saneamento e controle de poluição. Evidencia-se, também, a urgência na implantação de programas habitacionais de enfrentamento à precariedade domiciliar e programas de Assessoria Técnica colaborativa em Habitação de Interesse Social.

Ações de gestão compartilhada com o uso de tecnologias agroecológicas associadas a EAN devem ser um dos caminhos de enfrentamento do problema da fome influenciando nas condições de um habitat saudável. Para Vitória se faz necessária a implementação destas medidas nas áreas mais afetadas pela COVID-19 que coincidem com aquelas onde residem as populações mais vulneráveis, cujas habitações não são adequadas para o isolamento social e os devidos cuidados na prevenção da doença conforme preconiza a OMS.

Complementarmente, aponta-se a necessidade de incorporar estratégias de desenvolvimento e produção de habitação sustentável de baixo custo, com base em Tecnologias Sociais (TS), enquanto processo inclusivo e de mudança social, de modo a melhorar os alojamentos existentes e auxiliar a concepção de novas habitações. Em resumo, é necessário criar uma
Figura 10. Mapa de

Quantidade de imóveis não

ligados à rede de esgoto, por bairros, em Vitória/ES.

Fonte: Os autores, 2020. 
cidade mais resiliente, sustentável e equânime para todos, independente da renda e da classe social.

\section{Referências Bibliográficas}

AGROECOS. Economia Solidária e Agroecologia. Brasil, 2020. Disponível em: https://projetoagroecos.wixsite.com/meusite/sobre. Acesso em: abr. 2021.

ARQUITETURA NA PERIFERIA - ANP. O Projeto. Belo Horizonte, 2021. Disponível em: https://arquiteturanaperiferia.org.br/. Acesso em: 02 abr. 2021.

BENFEITORIA. Casinha para o Sr. Manoel no Território do Bem Vitória ES. Vitória, 2020. Disponível em: $\quad$ https://benfeitoria.com/casinha-para-o-sr-manoel-no-territorio-do-bem-vitoria-esh1y?ref=benfeitoria-pesquisa-projetos\&fbclid=IwAR15Didsozi6-

XFWhdpCOuWAJHXrm5pFbJPi541VDz3AmqIK12mZvVA1-Yk. Acesso em: 02 abr. 2021.

BID. Banco Interamericano de Desenvolvimento. Programa de requalificação urbana e segurança cidadã de Vitória. Relatório de Avaliação Ambiental e Social - RAAS. Vitória, Espírito Santo, 2018.

BRASIL. Lei $n^{\circ}$ 13.979, de 6 de fevereiro de 2020. Dispõe sobre as medidas para enfrentamento da emergência de saúde pública de importância internacional decorrente do coronavírus responsável pelo surto de 2019. Diário Oficial da República Federativa do Brasil. Brasília, Distrito Federal, 2020. Disponível em: https://www.in.gov.br/en/web/dou/-/lei-n-13.979-de-6-de-fevereiro-de-2020242078735. Acesso em jul. 2020.

BRASIL. Ministério da Saúde. Secretaria de Vigilância em Saúde. Departamento de Análise em Saúde e Vigilância de Doenças Não Transmissíveis. Vigitel Brasil 2019: vigilância de fatores de risco e proteção para doenças crônicas por inquérito telefônico. Estimativas sobre frequência e distribuição sociodemográfica de fatores de risco e proteção para doenças crônicas nas capitais dos 26 estados brasileiros e no Distrito Federal em 2019. Ministério da Saúde. Brasília: Ministério da Saúde, 2020a. Disponível em: http://www.crn1.org.br/wp-content/uploads/2020/04/vigitelbrasil-2019-vigilancia-fatores-risco.pdf?×53725. Acesso em: out. 2020.

BRASIL. Ministério da Saúde. Painel Coronavírus. Brasília: Ministério da Saúde, 2021. Disponível em: https://covid.saude.gov.br/. Acesso em: 08 abr. 2021.

BRCIDADES. Núcleo Espírito Santo. Cidades Inclusivas: uma pauta para as eleições capixabas. Vitória, 2020.

BRITO, P. D; GONÇALVES, J. L.; SILVA, P. S.; CARDOSO, C. S. A.; SILVA, M. P.; BACELO, A. C.; ESPÍRITO SANTO, R.; ALMEIDA, C. F. Educação alimentar e nutricional para o controle de comorbidades em pessoas com doenças infecciosas. Revista Brasileira em Promoção da Saúde, Fortaleza, vol. 30, n. 1, 2017. Disponível em: https://www.redalyc.org/jatsRepo/408/40851313019/html/index.html. Acesso em: jan. 2021.

COELHO, A. L. N. Geotecnologias aplicadas na distribuição espacial dos aterros da cidade de Vitória (ES). Caderno de Geografia, v. 27, n. 51, p. 760-775, 2017. DOI: https://doi.org/10.5752/p.23182962.2017v27n51p760. Disponivel em: http://periodicos.pucminas.br/index.php/geografia/article/view/p.2318-2962.2017v27n51p760.

Acesso em: ago. 2020.

DOW, K. Exploring differences in our common future(s): the meaning of vulnerability to global environmental change. Geoforum 1992; 23(3):417-436. Disponível em: https://doi.org/10.1016/0016-7185(92)90052-6. Acesso em: ago. 2020. 
ESPÍRITO SANTO, Superintendência Estadual de Comunicação Social do Espírito Santo - SECOM. Painel COVID-19 Estado do Espírito Santo, 2020. Disponível em: https://coronavirus.es.gov.br/. Acesso em: 05 ago. 2020.

FAJERSZTAJN, L.; VERAS, M.; SALDIVA, P. H. N. Como as cidades podem favorecer ou dificultar a promoção da saúde de seus moradores? Estudos Avançados, [S. I.], v. 30, n. 86, p. 7-27, 2016. Disponivel em: https://www.revistas.usp.br/eav/article/view/115078. Acesso em: 3 abr. 2021.

FARIA, A. L. B; CHAIA, V. Os institutos liberais e a consolidação da hegemonia neoliberal na América Latina e no Brasil. Cadernos Metrópole, São Paulo, v. 22, n. 49, p. 1059-1080, Dec. 2020. Disponível em: $\quad$ http://www.scielo.br/scielo.php?script=sci_arttext\&pid=S223699962020000301059\&lng=en\&nrm=iso>. Acesso em: 06 abr. 2021. Epub Aug 19, 2020. http://dx.doi.org/10.1590/2236-9996.2020-4917.

FEITOZA, T. M. O; CHAVEZ, A. M.; MUNIZ, G. T. S.; CRUZ, M. C. C.; CUNHA JUNIOR, I. F. Comorbidades e Covid-19: uma revisão integrativa. Revista Interfaces: Saúde, Humanas e Tecnologia, Recife, v. 8, n.3, p. 711-723, 2020. Disponível em: https://interfaces.leaosampaio.edu.br/index.php/revista-interfaces/article/view/800. Acesso em: jan. 2021.

FILETTI, M. Projeto reforma casas de famílias vulneráveis ao coronavírus. 2020. Disponível em: https://calangonoticias.com.br/projeto-reforma-casas-de-familias-vulneraveis-ao-coronavirus/.

Acesso em: 08 abr. 2021.

FUNDAÇÃO JOÃO PINHEIRO. Metodologia do déficit habitacional e da inadequação de domicílios no Brasil - 2016-2019. Belo Horizonte: Fundação João Pinheiro (FJP), 2021. Disponível em: http://novosite.fjp.mg.gov.br/wp-content/uploads/2020/12/04.03_Relatorio-Metodologia-doDeficit-Habitacional-e-da-Inadequacao-de-Domicilios-no-Brasil-2016-2019-v-1.0_compressed.pdf. Acesso em 08 abr. 2021.

FUNDAÇÃO OSWALDO CRUZ - FIOCRUZ. Covid-19/Perguntas e respostas. Brasil, Ministério da Saúde, 2021. Disponível em: https://portal.fiocruz.br/coronavirus/perguntas-e-respostas. Acesso em: 06 de abr. 2021.

HARROUK, C. Public Spaces and the Challenges of Covid-19: UN-Habitat's Small-Scale Urban Responses in Vietnam, Bangladesh and India. 24 fev. 2020. ArchDaily. Disponível em: https://www.archdaily.com/957524/public-spaces-and-the-challenges-of-covid-19-un-habitatssmall-scale-urban-responses-in-vietnam-bangladesh-and-india. Acesso em abr. 2021.

INSTITUTO BRASILEIRO DE GEOgRAFIA E ESTATístiCA - IBGE. Censo Demográfico 2010. Características da população e dos domicílios: resultados do universo. Rio de Janeiro: IBGE, 2010. Disponível em: Sistema IBGE de Recuperação Automática - SIDRA. Acesso em: 08 ago. 2020.

INSTITUTO BRASILEIRO DE GEOGRAFIA E ESTATÍSTICA - IBGE. IBGE divulga as estimativas da população dos municípios para 2020. Brasil, Agência IBGE Notícias, 2019. Disponível em: https://agenciadenoticias.ibge.gov.br/agencia-sala-de-imprensa/2013-agencia-de-

noticias/releases/28668-ibge-divulga-estimativa-da-populacao-dos-municipios-para-2020. Acesso em: 08 jul. 2020.

INSTITUTO BRASILEIRO DE GEOGRAFIA E ESTATÍSTICA - IBGE. Aglomerados subnormais 2019: Classificação preliminar e informações de saúde para o enfrentamento à COVID-19. Notas Técnicas. Rio de Janeiro, Diretoria de Geociências. Coordenação de Geografia e Meio Ambiente, 2020. Disponível em: https://agenciadenoticias.ibge.gov.br/media/com_mediaibge/arquivos/f9d10a1135cdaa0e845108f 06b1c00f1.pdf. Acesso em: 08 jul. 2020. 
INSTITUTO BRASILEIRO DE GEOGRAFIA E ESTATÍSTICA - IBGE. Cidades e Estados. Brasil, 2021. Disponível em: https://www.ibge.gov.br/cidades-e-estados/es/vitoria.html. Acesso em: abr. 2021.

INSTITUTO BRASILEIRO DE GEOGRAFIA E ESTATíSTICA - IBGE. Brasil/Espírito Santo/Vitória. Brasil, 2021a. Disponível em: https://cidades.ibge.gov.br/brasil/es/vitoria/panorama. Acesso em: abr. 2021.

INSTITUTO DE APOIO À PESQUISA E AO DESENVOLVIMENTO JONES DOS SANTOS NEVES - IPES. Governo do Estado do Espírito Santo. Secretaria de Estado do Planejamento. Região Metropolitana da Grande Vitória dinâmica urbana na década de 90. Ipes: Vitória, 2001. Disponível em: http://www.ijsn.es.gov.br/ConteudoDigital/20120828_646_rmgvdinamicaurbananadecadade90.pd f. Acesso em: 08 jul. 2020.

INSTITUTO JONES DOS SANTOS NEVES - IJSN. Implantação de projetos de grande porte no Espírito Santo: análise do quadro socioeconômico e territorial na fronteira de expansão metropolitana sul capixaba. IJSN: Vitória, 2011a.

INSTITUTO JONES DOS SANTOS NEVES - IJSN. Mapeamento das áreas periurbanas do Espírito Santo. IJSN, Vitória, 2011b. Disponível em: http://www.ijsn.es.gov.br/ConteudoDigital/20120821_853_ijsn_td24.pdf. Acesso em: 08 jul. 2020.

KAPP, S. Grupos sócio-espaciais ou a quem serve a assessoria técnica. Revista Brasileira de Estudos Urbanos e Regionais, São Paulo, v. 20, n. 2, p. 221-236, ago. 2018. DOI: https://doi.org/10.22296/2317-1529.2018v20n2p221. Disponível em: http://www.scielo.br/scielo.php?script=sci_arttext\&pid=S231715292018000200221\&lng=pt\&nrm=iso. Acesso em: 20 jan. 2021.

KAPP, S.; CARDOSO, A. L. Marco teórico da Rede Finep de Moradia e Tecnologia Social - Rede Morar T.S. Risco - Revista de Pesquisa em Arquitetura e Urbanismo, [S. I.], n. 17, p. 94-120, 2013. DOI: https://doi.org/10.11606/issn.1984-4506.v0i17p94-120. Disponível em: https://www.revistas.usp.br/risco/article/view/83050. Acesso em: 20 jan. 2021.

OPEN KNOWLEDGE BRASIL - OKBR. Índice de transparência da COVID-19 2.0. Brasil, 2020. Disponível em: https://transparenciacovid19.ok.org.br/. Acesso em: 02 ago. 2020.

PREFEITURA MUNICIPAL DE VITÓRIA. Plano de Metas, Vitória 2018-2020. Vitória, 2020. Disponível em: https://planodemetas.vitoria.es.gov.br/. Acesso em: abr. 2021.

PREFEITURA MUNICIPAL DE VITÓRIA. Vitória entre as três cidades do país em qualidade de vida e infraestrutura. Vitória, 2015. Disponível em: https://www.vitoria.es.gov.br/noticia/vitoria-e-asegunda-melhor-cidade-do-litoral-brasileiro-para-se-viver-18114. Acesso em: abr. 2021.

PREFEITURA MUNICIPAL DE VITÓRIA - PMV. Secretaria Municipal de Gestão Estratégica. Terra Mais Igual: Um programa participativo de desenvolvimento humano e urbano. Fábrica de Ideias: Vitória, 2014.

RIBEIRO-SILVA, R. C; PEREIRA, M.; CAMPELLO, T.; ARAGÃO, E., GUIMARÃES, J. M. M.; FERREIRA, A. J. F.; BARRETO, M. L.; SANTOS, S. M. C. Implicações da pandemia COVID-19 para a segurança alimentar e nutricional no Brasil. Ciênc. saúde coletiva, Rio de Janeiro, v. 25, n. 9, p. 3421-3430, set. 2020. DOI: https://doi.org/10.1590/1413-81232020259.22152020. Disponível em: http://www.scielo.br/scielo.php?script=sci_arttext\&pid=S1413-

81232020000903421\&lng=pt\&nrm=iso. Acesso em: 21 jan. 2021. Epub 28-Ago-2020.

SALDIVA, P. Vida urbana e saúde. São Paulo: Contexto, 2018.

SANTOS, B. S. A cruel pedagogia do vírus. Almedina: Coimbra, 2020. 
TAVOLARI, B. DIREITO À CIDADE: UMA TRAJETÓRIA CONCEITUAL. Novos estudos CEBRAP, São Paulo, v. 35, n. 1, p. 93-109, Mar. 2016. DOI: http://dx.doi.org/10.25091/s0101$3300201600010005 . \quad$ Disponível http://www.scielo.br/scielo.php?script=sci_arttext\&pid=S010133002016000100005\&lng=en\&nrm=iso. Acesso em abril de 2021.

UN-HABITAT. United Nations Human Settlements Program. Urban farming and art help vulnerable people in Fiji during the COVID pandemic. 2020. Disponível em: https://unhabitat.org/urban-farming-and-art-help-vulnerable-people-in-fiji-during-the-covidpandemic. Acesso em abr. 2021.

Liziane de Oliveira Jorge liziane.jorge@ufes.br

Luciene Pessotti

lulucienepessotti@gmail.com

URBAN SYSTEM. Ranking connected smart cities edição 2020. Urban System, São Paulo, 2020. Disponível em: https://ranking.connectedsmartcities.com.br/. Acesso em 08 ago. 2020.

\title{
Notas
}

\begin{abstract}
' Discurso de abertura do Diretor Geral da Organização Mundial da Saúde (OMS), sobre a situação da COVID-19 em contexto mundial, no dia 11 de março de 2020, em Genebra, Suíça. Tedros Adhanom Ghebreyesus reconhece publicamente a pandemia decorrente da disseminação internacional do novo coronavírus. $O$ discurso refere-se à velocidade de aceleração alarmante do contágio e das mortes decorrentes da COVID-19 e sinaliza a necessidade dos países na adoção de medidas urgentes e agressivas para o controle da doença. Disponível em:

https://www.who.int/dg/speeches/detail/who-director-general-s-opening-remarks-at-the-mediabriefing-on-covid-19---11-march-2020. Acesso: 22 jun. 2020
\end{abstract}

ii Segundo o portal da Fiocruz (FIOCRUZ, 2021), os coronavírus causam infecções respiratórias em seres humanos e em animais, de leves a moderadas. Entretanto, o novo coronavírus é uma nova cepa do vírus (2019-nCoV), notificada em humanos pela primeira vez na China. Através do fenômeno de transbordamento zoonótico, o coronavírus que acomete morcegos sofreu uma mutação e passou a infectar humanos. O novo coronavírus é transmissível através de secreções contaminadas, do contato pessoal próximo, e do toque em objetos ou superfícies contaminados, seguido de contato com a boca, o nariz ou os olhos. Em se tratando de uma doença nova, os cientistas estão descobrindo uma série de fatores relacionados a ela (FIOCRUZ, 2021). Portanto, na ocasião da deflagração da pandemia pela OMS, em março de 2020, havia muito para se investigar. Em Vitória o fenômeno da disseminação do novo coronavírus aconteceu conforme indica as descobertas científicas mencionadas, ou seja, pelo contato pessoal próximo e contágio pelo contato com superfícies contaminadas, abrangendo todo o município.

iii O conceito de baixa-renda empregado neste trabalho compreende a realidade socioeconômica de famílias com renda familiar mensal de até 3 salários mínimos. Esta faixa abrange parte das políticas públicas e benefícios sociais do Brasil, distribuída em programas e projetos, como o CADÚNICO (Cadastro que identifica e caracteriza a população de baixa renda); Programa Minha Casa Minha Vida; Programa Bolsa Família; Tarifa Social de Energia Elétrica; Tarifa Social de água, dentre outros.

iv Segundo a Fundação João Pinheiro (2021, p. 73), domicílios rústicos são "[...] aqueles sem paredes de alvenaria ou madeira aparelhada, o que resulta em desconforto e risco de contaminação por doenças, em decorrência das suas condições de insalubridade". 